\title{
Erratum: Histone chaperones: an escort network regulating histone traffic
}

Leanne De Koning, Armelle Corpet, James E Haber \& Geneviève Almouzni

Nat. Struct. Mol. Biol. 14, 997-1007 (2007); published online 5 November 2007; corrected after print 5 November 2007

In the print version of this article, the reference to the Review by Shilatifard and co-workers is incorrect. On page 1002, it should be referred to as 'Bhaumik et al. ${ }^{68}$ ' and on page 1006 , the reference citation should read:

68. Bhaumik, S.R., Smith, E. \& Shilatifard, A. Covalent modifications of histones during development and disease pathogenesis. Nat. Struct. Mol. Biol. 14, 1008-1016 (2007). 